\title{
Numerical modeling of robust production scenarios from shared oil reservoirs
}

\author{
Sara Shokrolahzadeh-Behbahani • \\ Mahdi Zeinali-Hasanvand • Mohammad-Ali Ahmadi
}

Received: 7 February 2014/ Accepted: 5 May 2014/Published online: 25 May 2014

(c) The Author(s) 2014. This article is published with open access at Springerlink.com

\begin{abstract}
A reservoir that has formed through millions of years of sedimentation almost never conforms to the established borderlines that define political entities or legal jurisdictions of neighboring countries. The term shared reservoir is given to such hydrocarbon deposits. After the discovery of shared reservoirs, the neighboring countries could jointly develop a cross-border hydrocarbon deposit or disagree on any framework for unitizing or jointly developing the reservoir. Furthermore, in order for any negotiation to take place, the contending sides need to settle on an unbiased agreement. This can only be done after the term "unbiased" is defined quantitatively in technical terms. Although defining a reservoir before thorough exploration is challenging and rather unreliable, understanding the behavior of shared reservoirs is highly valued since many reservoirs around the globe, including the world's largest condensate gas reservoir, in under such collaborative ownership. It is evident that optimized production from such reservoirs will benefit their rightful possessors and the rest of the world. This study investigates all main factors that influence production from a shared oil reservoir and demonstrates how each neighboring country is affected by variations of each of these factors. Displays of simulated reservoir at potential production conditions complement our quantitative analysis throughout this study.
\end{abstract}

S. Shokrolahzadeh-Behbahani · M.-A. Ahmadi ( $₫)$ Department of Petroleum Engineering, Ahwaz Faculty of Petroleum Engineering, Petroleum University of Technology, Ahwaz, Iran

e-mail: ahmadi6776@yahoo.com

M. Zeinali-Hasanvand

Research Institute of Petroleum Industry (RIPI), Tehran, Iran
Keywords Quantitative analysis - Shared oil reservoir · Optimized production · Crude migration - Influential factors $\cdot$ Numerical modeling

\section{Introduction}

A hydrocarbon reservoir is a porous medium that has formed as a result of sedimentation over long periods of time. The organic matter buried beneath the sediments is pressurized and introduced to higher temperatures; this induces chemical changes to the organic matter and alters it to valuable substances such as coal, tar, oil and gas. Due to the heterogeneous nature of sedimentation layers and hydrocarbon migration, hydrocarbon reservoirs can exist at any geographical location (Hou et al. 2011). Therefore any hydrocarbon deposit may be found to intersect the boundary dividing two separate territories. Such reservoirs that are known as shared reservoirs will demonstrate indefinite hydraulic fluid connection and heterogeneity of the reservoir rock which can lead to crude migration across the boundary. This complicates matters when there are two countries contending for maximized production. The shared reservoirs are distributed all over the world. In the Middle East, the main Energy production place of world there are many numbers. In Table 1 list of some IranianNeighbors shared oil and gas reservoirs and their original hydrocarbon reserves are presented.

Maximum production from the shared reservoir, pressure maintenance, enhanced oil recovery (EOR) processes, improved oil recovery (IOR) processes and optimized production are controversial subjects to be discussed when considering dual ownership of a shared reservoir as there are no laws or regulations that could enforce conditions to prohibit fluid migration or cross-boundary production 
Table 1 List of shared hydrocarbon reservoirs of Iran and their original fluid and rock properties considered for simulated reservoir

\begin{tabular}{|c|c|c|c|c|}
\hline $\begin{array}{l}\text { Reservoir } \\
\text { name }\end{array}$ & Type & $\begin{array}{l}\text { Original oil in } \\
\text { place (million } \\
\text { barrel) }\end{array}$ & $\begin{array}{l}\text { Original gas in } \\
\text { place (billion Scf) }\end{array}$ & Countries \\
\hline $\begin{array}{l}\text { Naft } \\
\text { Shahr }\end{array}$ & Oil & 692 & - & Iran-Iraq \\
\hline Dehloran & Oil & 4,212 & - & Iran-Iraq \\
\hline Azadegan & Oil & 33,000 & - & Iran-Iraq \\
\hline Yadavaran & Oil & 12,200 & & Iran-Iraq \\
\hline Arash & Gas & 83.6 & 22.5 & $\begin{array}{l}\text { Iran- } \\
\quad \text { Koweit }\end{array}$ \\
\hline South Pars & Gas & 18,000 & 131.3 & $\begin{array}{l}\text { Iran- } \\
\text { Qatar }\end{array}$ \\
\hline Sasan & $\begin{array}{l}\text { Oil/ } \\
\text { gas }\end{array}$ & 4,073 & 0.183 & $\begin{array}{c}\text { Iran-Abo } \\
\text { Dubi }\end{array}$ \\
\hline Hengam & Gas & - & 22.4 & $\begin{array}{l}\text { Iran- } \\
\text { Oman }\end{array}$ \\
\hline
\end{tabular}

(Weems and Fallon 2012). Only a quantitative analysis on the factors that influence production and fluid migration within a shared reservoir can determine whether or not the rights of each country have been served in the dual production process. A more consequential matter that should be studied is whether joint management of the reservoir is sufficiently economical to encourage a cooperative reservoir development.

Due to the diverse physical characteristics of oil and gas, separate investigations need to be carried out on gas and oil reservoirs and extending results of one fluid to the other only allows a qualitative analysis between the two. To assess this goal, current research focuses on shared oil reservoirs while through this research, the fluid hydraulics within a shared reservoir by studying the equations that can be carried out to the fluid in a porous medium to figure out the dominating factors that impose the migration of hydrocarbons across the borderline illustrated along with details. Characteristics that tend to assist the migration of oil or affect it in some way are the rock properties (such as permeability and porosity), fluid properties (such as viscosity, compressibility and formation volume factor) and other characteristics like arrangement of producing wells, reservoir's tilt, the effectiveness of the aquifer and time. After study on each factor and the extent to which it contributes to oil migration, we analyze if and how co-managing the shared reservoir can promote the ultimate recovery. It is worth bearing in mind that Eclipse's 2009 Black oil model was carried out to achieve addressed goal of this research due to high computational time of simulation runs in compositional approach and low computational time in black oil approach.

\section{Fluid flow in porous media}

Through petroleum reservoirs, the relationship commonly carried out to figure out fluid flow in porous media is the equation proposed by Henry Darcy in 1856 while he assumed that steady state isothermal one-dimensional flow of incompressible fluid met:

$q=-\frac{k A}{\mu} \times \frac{\mathrm{d} P}{\mathrm{~d} x}$

where, $q, k, A, \mu, P$ and $x$ represent fluid flow rate $\left(\mathrm{m}^{3} / \mathrm{s}\right)$, rock permeability $\left(\mathrm{m}^{2}\right)$, rock cross sectional area $\left(\mathrm{m}^{2}\right)$, viscosity $(\mathrm{Pa} \times \mathrm{s})$, pressure $(\mathrm{Pa})$ and rock length $(\mathrm{m})$, correspondingly (Ayala and Kouassi 2007). For the cylindrical flow of semi-compressible fluids, the Darcy equation develops into Eq. 2:

$Q_{\mathrm{o}}=\left[\frac{0.00708 k h}{\mu_{\mathrm{o}} B_{\mathrm{o}} c_{\mathrm{o}} \ln \left(\frac{r_{\mathrm{e}}}{r_{\mathrm{w}}}\right)}\right] \ln \left[1+c_{\mathrm{o}}\left(p_{\mathrm{e}}-p_{\mathrm{wf}}\right)\right]$

where, $B_{\mathrm{o}}, C_{\mathrm{o}}, h, r_{\mathrm{e}}, r_{\mathrm{w}}, p_{\mathrm{e}}, p_{\mathrm{w}}, k, \mu_{\mathrm{o}}$ and $Q_{\mathrm{o}}$ are assigned to the oil formation volume factor (bbl/STB), oil compressibility $\left(\mathrm{psi}^{-1}\right)$, net formation thickness ( $\mathrm{ft}$ ), external (drainage) radius, wellbore radius, external pressure (psi), wellbore pressure (psi), permeability (millidarcy $(\mathrm{mD})$ ), viscosity $(\mathrm{cP})$ and oil flow rate (STBD), correspondingly (Ahmed and McKinney 2005). Furthermore, if a compressible fluid like as gas is under study, the Darcy equation for cylindrical flow geometry will be:

$Q_{\mathrm{g}}=\frac{k h\left(\psi_{\mathrm{e}}-\psi_{\mathrm{w}}\right)}{1422 T \ln \left(\frac{r_{\mathrm{e}}}{r_{\mathrm{w}}}\right)}$

where, $Q_{\mathrm{g}}$ and $T$ are assigned to the gas flow rate in Mscf/ day and temperature in ${ }^{\circ} R$ units, respectively. In the relationship given by Eq. $3, \psi_{\mathrm{e}}$ is called the real gas potential and is defined as following expression:

$m(p)=\psi=\int_{0}^{p}\left(\frac{2 p}{\mu_{\mathrm{g}} z}\right) \mathrm{d} p \quad \mathrm{psi}^{2} / \mathrm{cP}$

As these equations suggest, rock properties (such as porosity and permeability) and fluid properties (such as viscosity, compressibility and oil formation volume factor) impact the produced amount of oil and gas. In addition to these properties, the pressure decline trend and time play significant roles.

Moreover, by combining continuity equations for a cylindrical reservoir with the Darcy equation, we derive the diffusivity equation which is a second degree differential equation that correlates pressure as a function of time and radius of investigation. 
$\frac{\partial^{2} p}{\partial r^{2}}+\frac{1}{r} \frac{\partial p}{\partial r}=\frac{1}{\eta} \frac{\partial p}{\partial t}$

where:

$\eta=\frac{0.000264 k}{\phi \mu c_{\mathrm{t}}}$

where $\phi$ and $c_{\mathrm{t}}$ are rock porosity and total compressibility factor $\left(\mathrm{psi}^{-1}\right)$, respectively.

According to the diffusivity equation, pressure decline in the reservoir is not associated with the production flow rate and depends solely on physical characteristics of reservoir rock and fluid. The diffusivity equation for gases is derived from Eq. 5 by replacing the real gas potential $(\psi)$ by pressure as follows (Al-Hussainy et al. 1966):

$\frac{\partial^{2} \psi}{\partial r^{2}}+\frac{1}{r} \frac{\partial \psi}{\partial r}=\frac{\phi \mu c_{\mathrm{t}}}{0.000264 k} \frac{\partial \psi}{\partial t}$

Another matter of concern in oil reservoirs is the effect of boundary. We cannot determine production conditions until the radius of investigation has reached the drainage radius. After which, the production can continue in any of the three following states:

1. The reservoir will continue to produce with stable pressure and flow rate.

2. The pressure will decrease linearly at the wellbore.

3 . The pressure and flow rate will begin to reduce nonlinearly with time.

The Darcy equation states that if the pressure decline remains constant throughout the fluid's path (for example for having an active aquifer), fluid velocity will also be constant $(v=Q / A)$ and water will replace produced oil. If the aquifer is ineffective or non-existent, fluid velocity is high in the vicinity of wellbore and low in more distant areas. Eventually, the fluid velocity will decline all throughout the reservoir.

Considering velocity and the presence of an aquifer in the reservoir boundary, the configuration of production wells is of importance, especially when we cannot drill wells further than the borderline. Alternatively, if the aquifer is active, well configuration does not have much influence on fluid flow because the velocity of flow is linear and equal all throughout the reservoir.

Thus, based on equations and discussions provided, the following are identified as factors that influence fluid flow in a shared reservoir:

1. Well configuration

2. Production time

3. Slope of reservoir

4. Aquifer performance

5. Rock properties in each territory

6. Fluid properties in each territory

\section{Analyzing production from a shared oil reservoir}

To analyze the production from a shared reservoir, we will simulate various conditions of production and investigate the role of each identified variable that may influence production.

In Eqs. 1 through 7, variables such as pressure, permeability, compressibility and etc. have been considered in their simplest forms. The fluid compressibility is a theoretically determined sum of fluid compressibility (water, oil and gas) multiplied by saturation of each phase. Permeability also varies with fluid saturation. Furthermore, gravity's role should be incorporated into the equations if the reservoir is tilted. To deal with complications of this kind of reservoir, a simulator, namely ECLIPSE, was used.

Eclipse's Tracer software was carried out to introduce a reservoir with $20 \mathrm{~km}$ in length, $100 \mathrm{~m}$ in thickness and $8 \mathrm{~km}$ in width. The porosity and permeability of homogenous reservoir rock are originally considered $13 \%$ and $100(\mathrm{mD})$, correspondingly. Implemented fluid properties and other relevant information such oil/water and gas/oil relative permeabilities which required for graph evaluation are demonstrated in Table 2; Figs. 1 and 2. The oil on both sides of the supposed border line is initially considered identical eliminate its influence. Figure 3 exhibits the reservoir before production has begun. Two proposed producing wells, the border line separating neighboring countries and the reservoir bulk itself are demonstrated.

The program's data file for the reservoir is available in the appendix for implementation for future augmentation. To figure out the effect of each indentified production variables, we modified the input data fed to the simulator. The results are illustrated in details as below sections.

Table 2 Original fluid and rock properties considered for simulated reservoir

\begin{tabular}{lll}
\hline Property & Quantity & Unit \\
\hline Irreducible water saturation & 0.2 & - \\
Irreducible oil saturation & 0.19 & - \\
Irreducible gas saturation & 0.1 & - \\
Bubble pressure & 2,800 & $\mathrm{Psia}$ \\
Gas in solution & 1,130 & $\mathrm{SCF} / \mathrm{STB}$ \\
Total compressibility & $1 \times 10^{-6}$ & $\mathrm{Psia}^{-1}$ \\
Formation water density & 63.01 & $\mathrm{lb}_{\mathrm{m}} / \mathrm{Cuft}$ \\
Dead oil density & 44.98 & $\mathrm{lb}_{\mathrm{m}} / \mathrm{Cuft}$ \\
Gas density & 0.0702 & $\mathrm{lb}_{\mathrm{m}} / \mathrm{Cuft}$ \\
Water viscosity & 0.96 & $\mathrm{cP}$ \\
Oil viscosity & 0.16 & $\mathrm{cP}$ \\
Gas viscosity & 1 & $\mathrm{cP}$ \\
\hline
\end{tabular}


Fig. 1 Relative permeability curves of gas and oil phases

Fig. 2 Relative permeability curves of oil and water phases

The effect of well configuration

\section{Symmetrical well configuration across borderline}

In the modeled reservoir we assume all fluid properties alike with only two producing wells, one well in each territory equidistant from the border line. According to the superposition principle, and acknowledging that pressure decline disseminates as production begins, we expect to see identical trends of pressure decline in both parts of the homogenous isotropic reservoir when well configuration is symmetrical across the assumed bisecting borderline. This means that oil within each territory is produced by its own producing well and no hydrocarbon migrates across the border. Figure 4 demonstrates oil saturation across the reservoir at various instances in time. The identicalness of production circumstances can be distinguished by similar saturations around producing wells. Analogous comparisons could be made via other parameters such as produced gas, pressures, and fluid movement by the border line as displayed in Figs. 5 and 6.

Based on results, we conclude that simultaneous production from an isotropic homogenous reservoir with similar well configuration on both sides of the borderline can lead to an evenhanded sharing of a shared reservoir. Needless to say, the reservoir may not be divided equally between neighboring countries and the borderline may not bisect the reservoir but other assumptions could be made to assure correspondence between production and share of reservoir. 


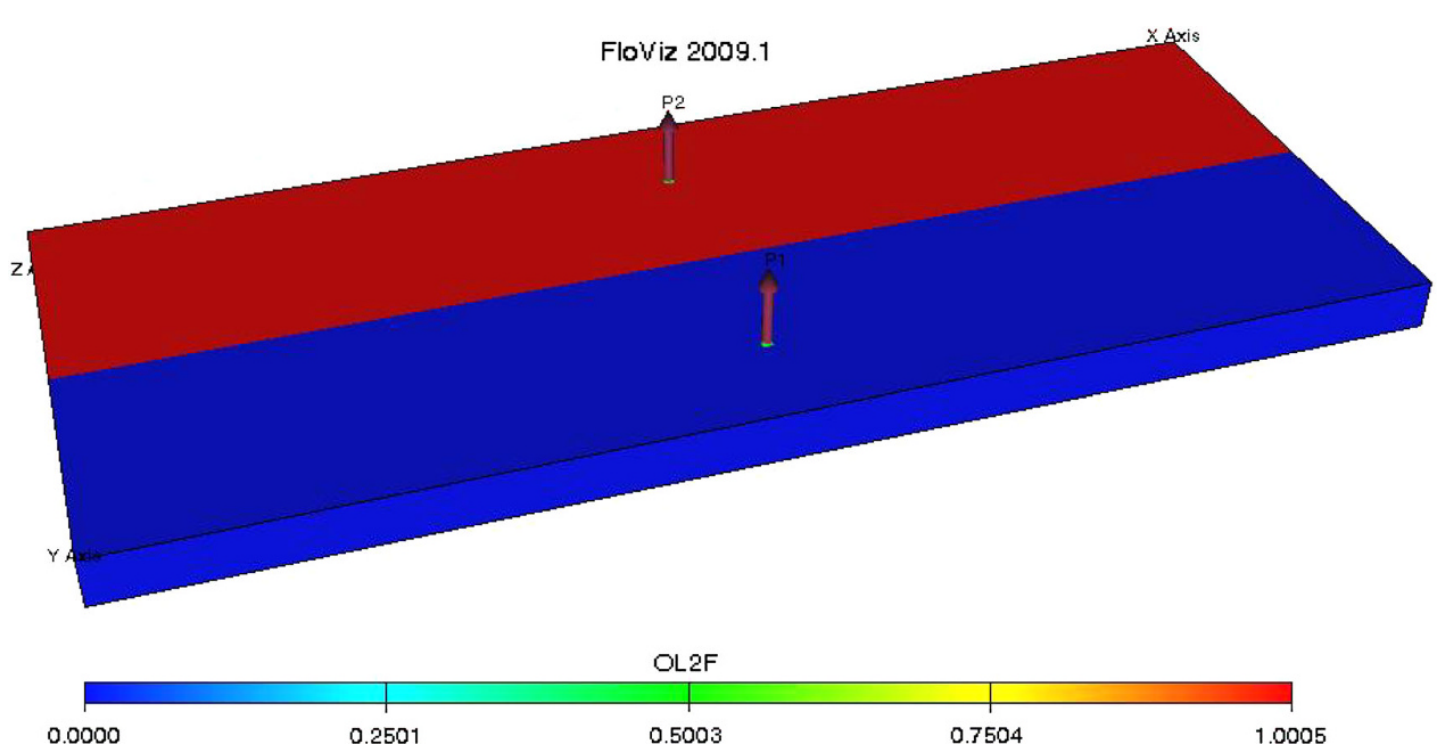

Fig. 3 Model of a shared hydraulically interconnected oil reservoir with one producing well in each of the two defined territories
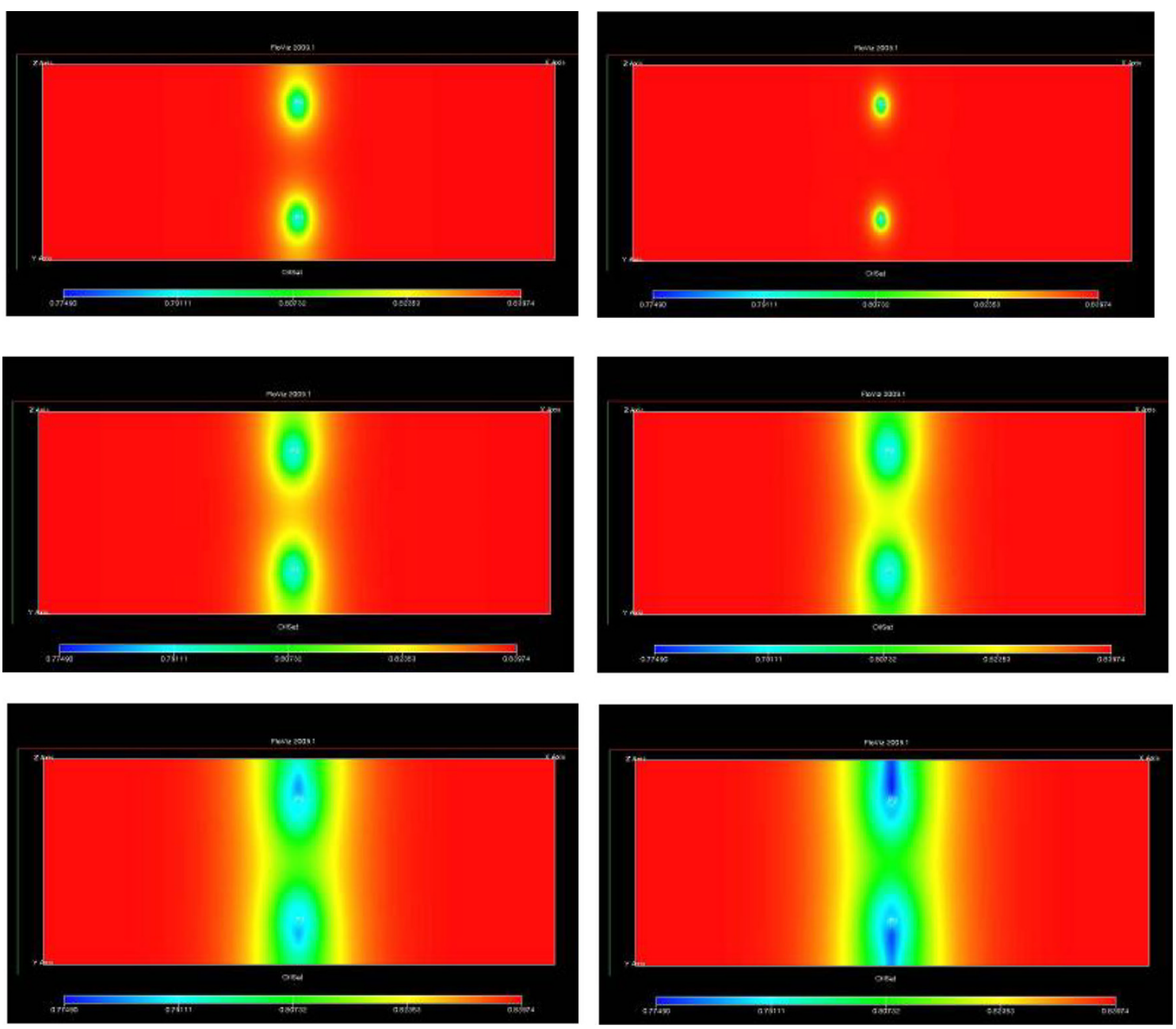

Fig. 4 Simulation results for symmetrical well configuration 


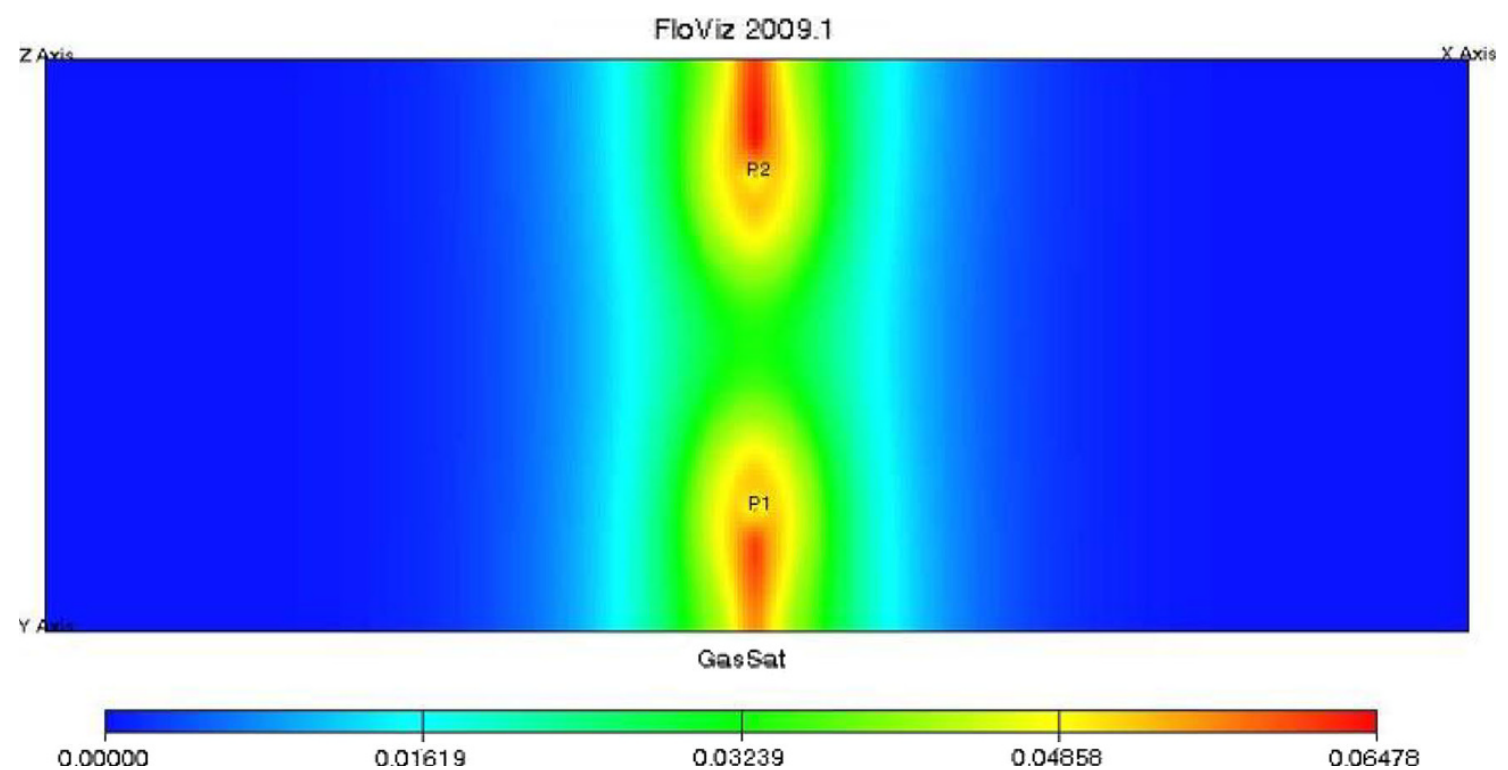

Fig. 5 Gas saturation in the environs of the two producing wells after production

Floviz 2009.1

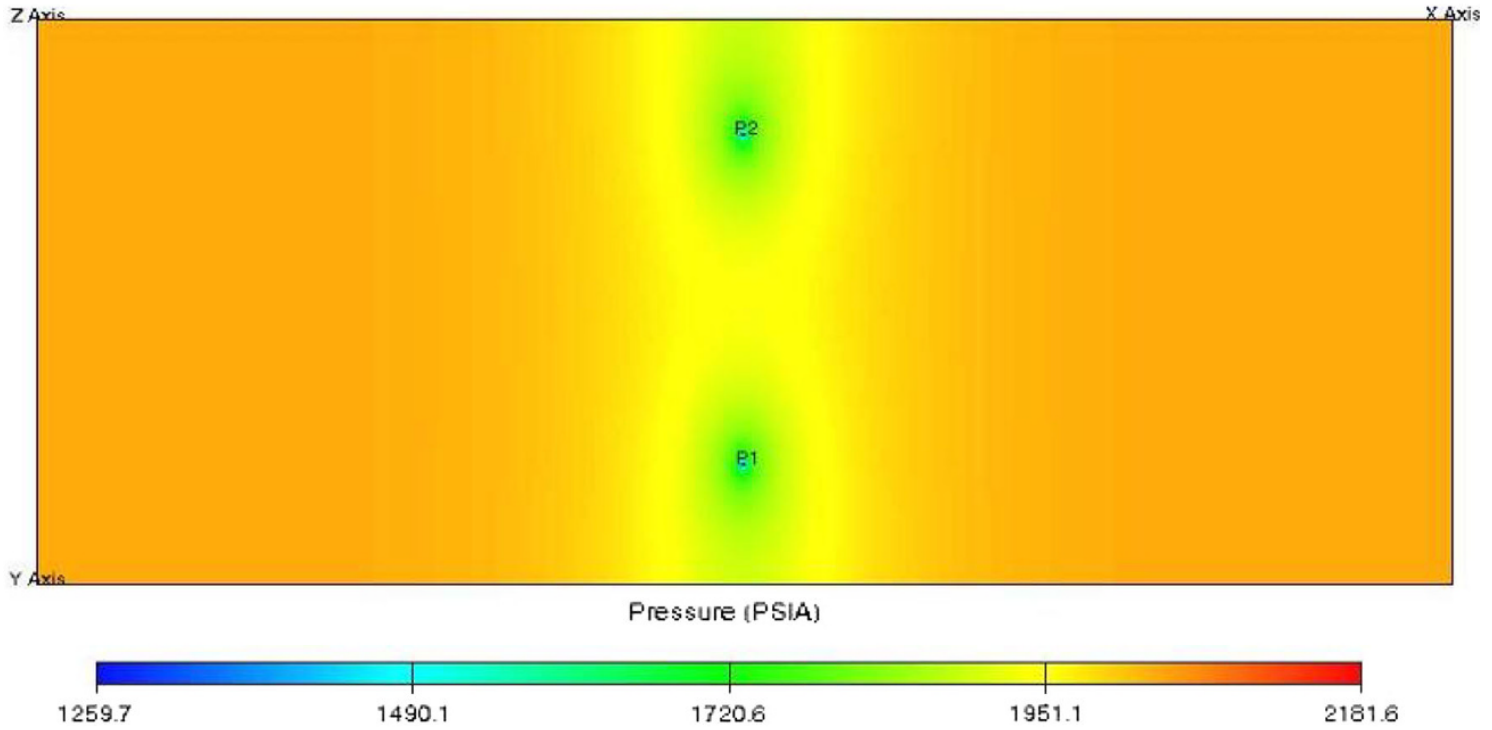

Fig. 6 Reservoir pressure in the environs of the two producing wells after production

\section{Asymmetrical well configuration across borderline}

To better investigate the role of well configuration on production from a shared oil reservoir, we define 10 producing wells within both territories producing at 160,000 STBD. The ten wells in the southern and northern countries are drilled 7,360 and $2,112 \mathrm{ft}$ away from the borderline, respectively. As demonstrated by Fig. 7 the wells closer to the boundary produce some oil from their neighboring territory while the more distant wells are unable to do the same. The cross-boundary production of the northern country is 6,000 STBD while the southern country is unable to produce any oil from its neighbor's share of the reservoir fluid.

The origin of this migration is explained through fluid flow equations and the diffusivity equation in particular. The radius of investigation of wells closer to the borderline will reach the borderline and begin production from the area sooner. Even after farther wells begin production from the area near the border, the pressure required for production will not stronger than the opposing pressures of nearer wells. To reduce the harm, the suffering country 


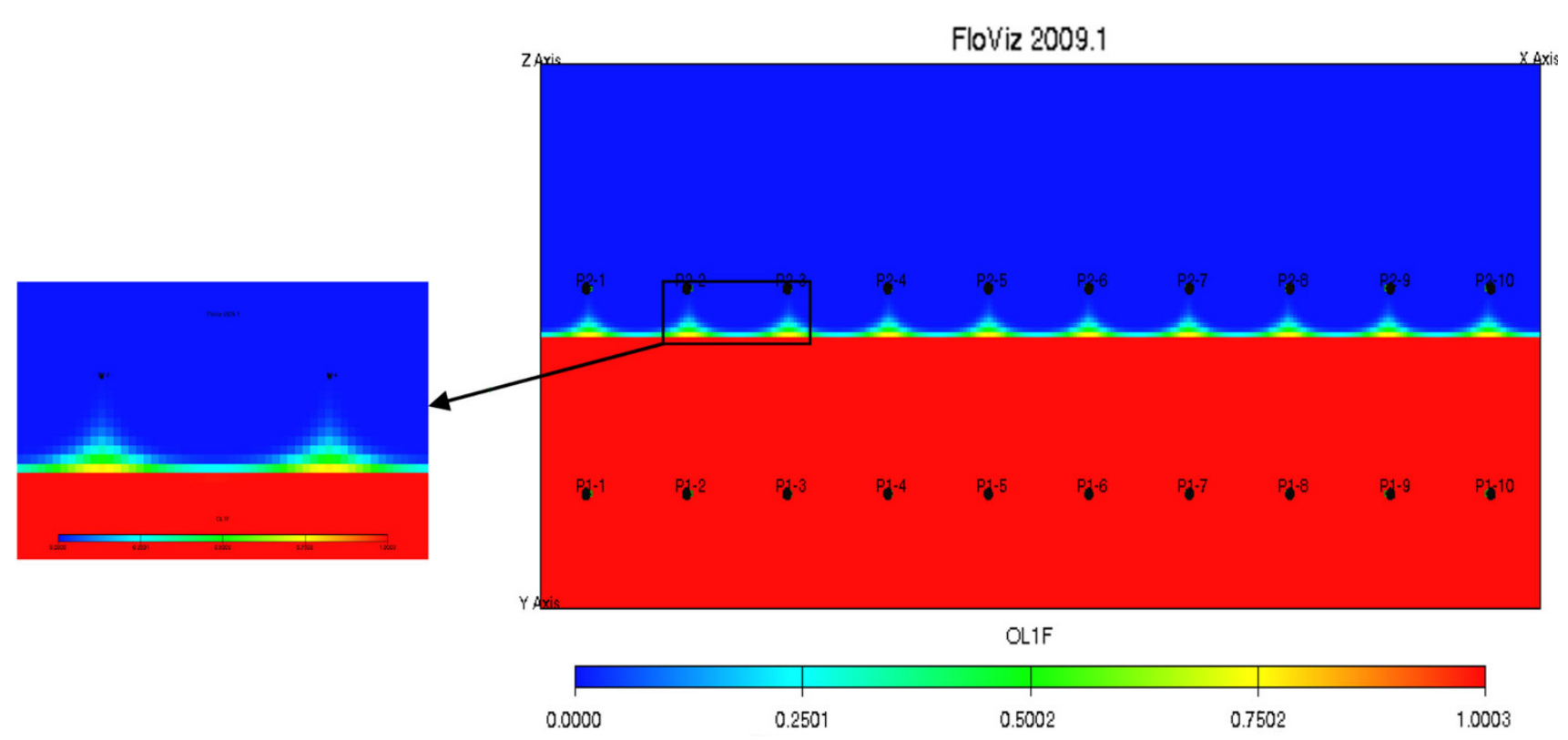

Fig. 7 The effect of asymmetrical well configuration on the oil saturation

may increase production flow rate to intensify the pressure decline or drill other wells at locations closer to the boundary.

Figure 8 demonstrates the reservoir in 40 years of production. Simulation results suggest that the country with wells farther away from the boundary has lower oil saturation and higher gas saturations in its side of the reservoir. Consequently, the country with farther wells will ultimately produce more gas, encounter more pressure decline and will have to abandon the reservoir sooner than the neighboring producer. Therefore, this country will not only lose migrating oil, it will be powerless to preserve optimum production conditions. Our investigations show that if the wells are located exactly on the boundary, as high as $50 \%$ of production consists of fluid originating from the neighbor's share of the shared reservoir. Figures 9 and 10 demonstrate a graphical illustration of our results.

The effect of time of production

Time is a variable in the diffusivity and Darcy equations and will therefore influence fluid flow. To determine the extent to which production time affects hydrocarbon migration, all variables other than time will be held constant. Two parallel rows of ten wells spaced $2 \mathrm{~km}$ away from the border line are assumed to produce 160,000 STBD from an isotropic homogenous shared reservoir while the southern country begins production 3 years earlier than its northern neighbor.
Figure 11 demonstrates the reservoir at initial conditions and oil migration 3, 9 and 18 years after beginning production from a shared reservoir. As revealed by the figure, oil migrates toward the country that has begun production sooner. But the consequences caused by the time lag are mostly noticeable when the second country begins production with similar rates. The diffusivity equation suggests that fluid on borderline is produced only after the drainage radius has reached the borderline. The time it takes for a point at radius $r$ to sense the pressure decline is (Ahmed and McKinney 2005):

$t \propto \frac{r^{2}}{\eta} \quad$ where $\quad \eta=\frac{0.000264 k}{\phi \mu c_{\mathrm{t}}}$

According to Eq. 8, the country that has delayed production can minimize losses for by drilling wells that are closer to the borderline.

Simulation results exhibit that even after both countries have begun producing, oil migration continues to occur. It will take almost 15 years for the effects of beginning production after various times to fade away, for our reservoir of study. After 15 years, both countries will be able to produce at equal rates, but the leading country will have ultimately produced more oil. Despite the fact that the second country begins production only 3 years after and eventually produces with higher rates for some time, it will still not be able to produce as much oil as its neighboring country. The hydraulic connection of fluid in reservoir and reservoir pressure will only allow the late producer to save its share from what's left in the reservoir. Therefore, the late producer can never make up for the lost time and continues to be 
Fig. 8 Effect of 20 wells configured asymmetrically in oil saturation (top), gas saturation (middle) and pressure (bottom) after 13 years of production
Floviz 2009.1

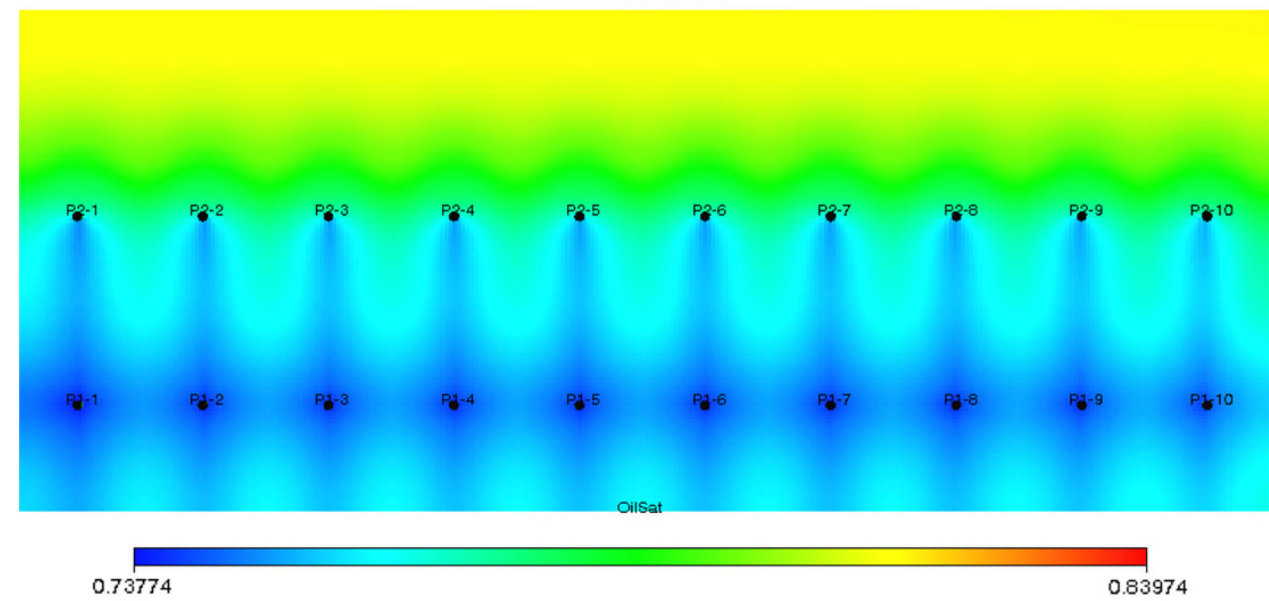

Floviz 2009.1

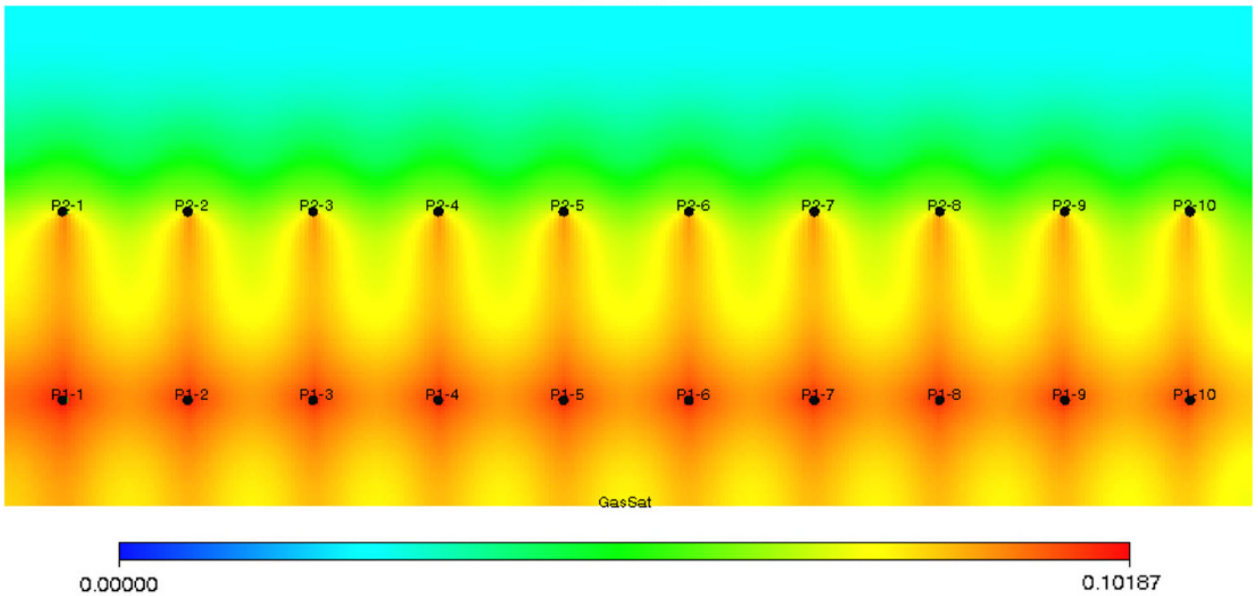

Floviz 2009.1

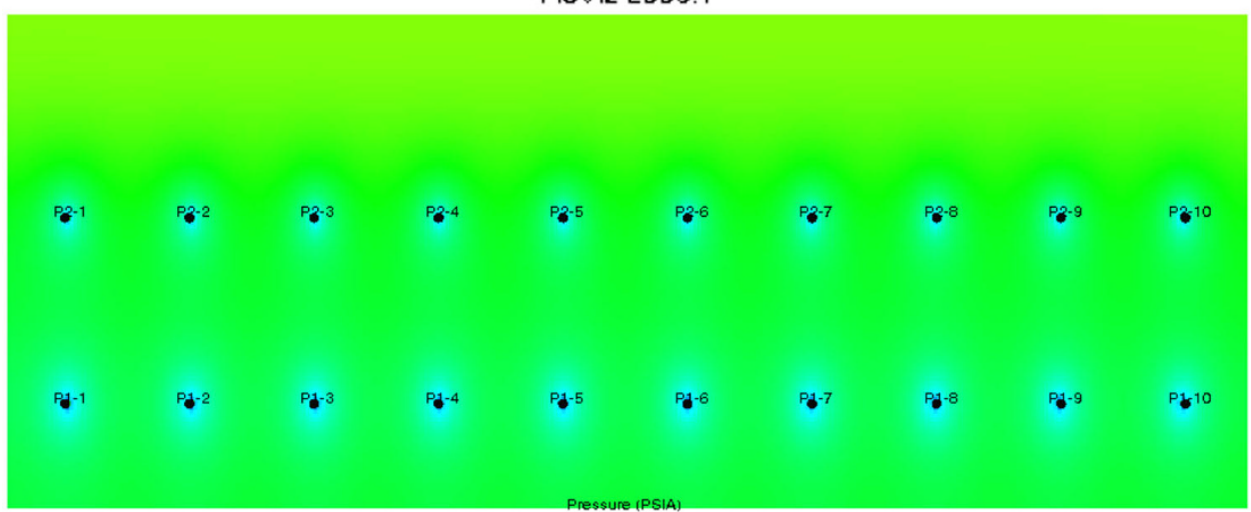

bereaved from their share of oil until they begin producing it. Figure 12 illustrates the simulation results.

To compare the effect of time, we increased the time lag from 3 to 6 years. The results were similar. By doubling the time lag, migration across boundary increased twice as much and the final production doubled for the leading country.
The effect of reservoir slope

If a reservoir is tilted, the Darcy and diffusivity equation for pressure will have to be corrected for gravitational forces. To investigate the effect of a reservoir slope, we simulated a reservoir with previous initial data and a dip 


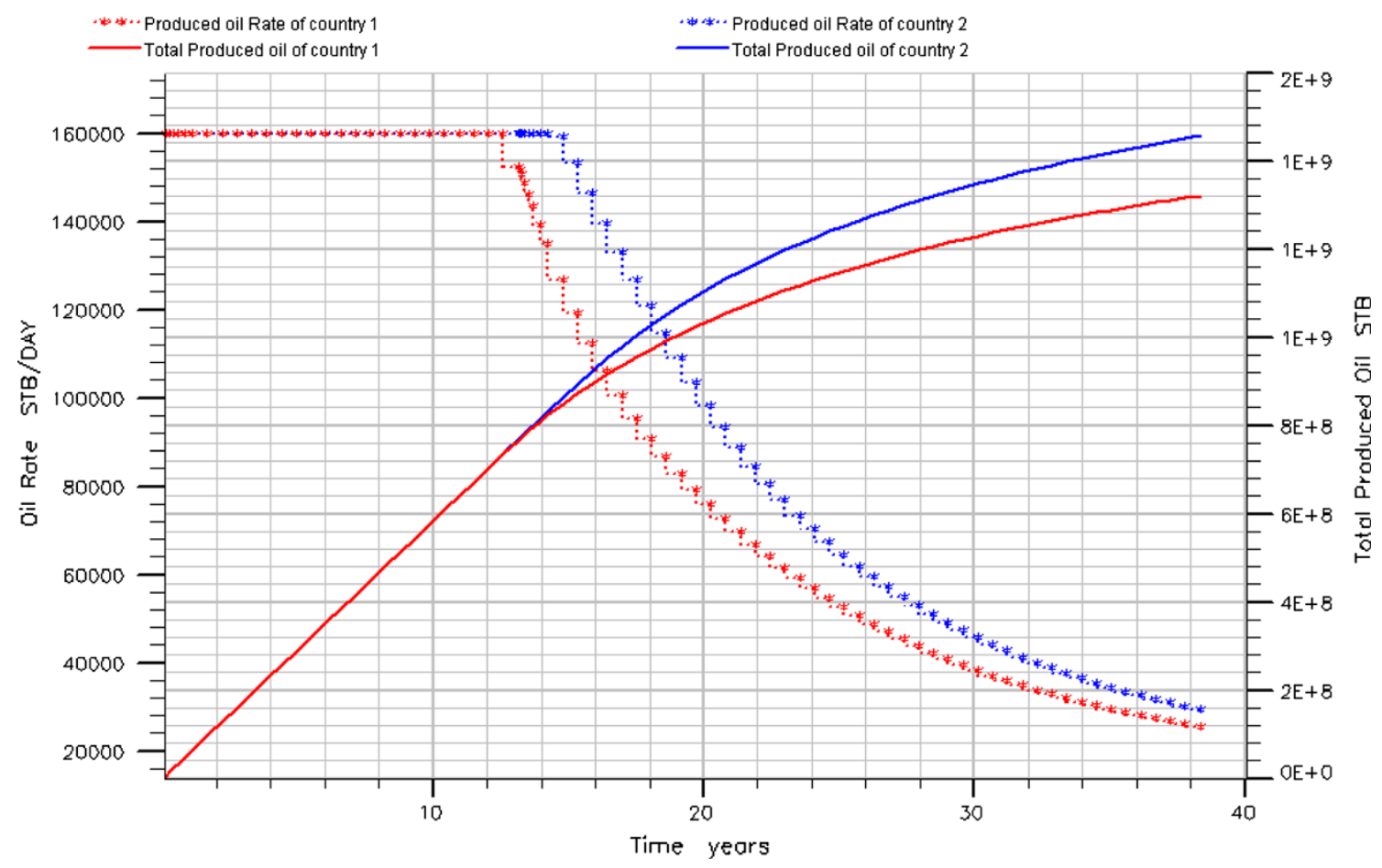

Fig. 9 Comparison of daily oil production and total oil production from asymmetrically located wells in the countries 1 and 2

Fig. 10 Comparison of oil production of each country from neighboring country's part of reservoir

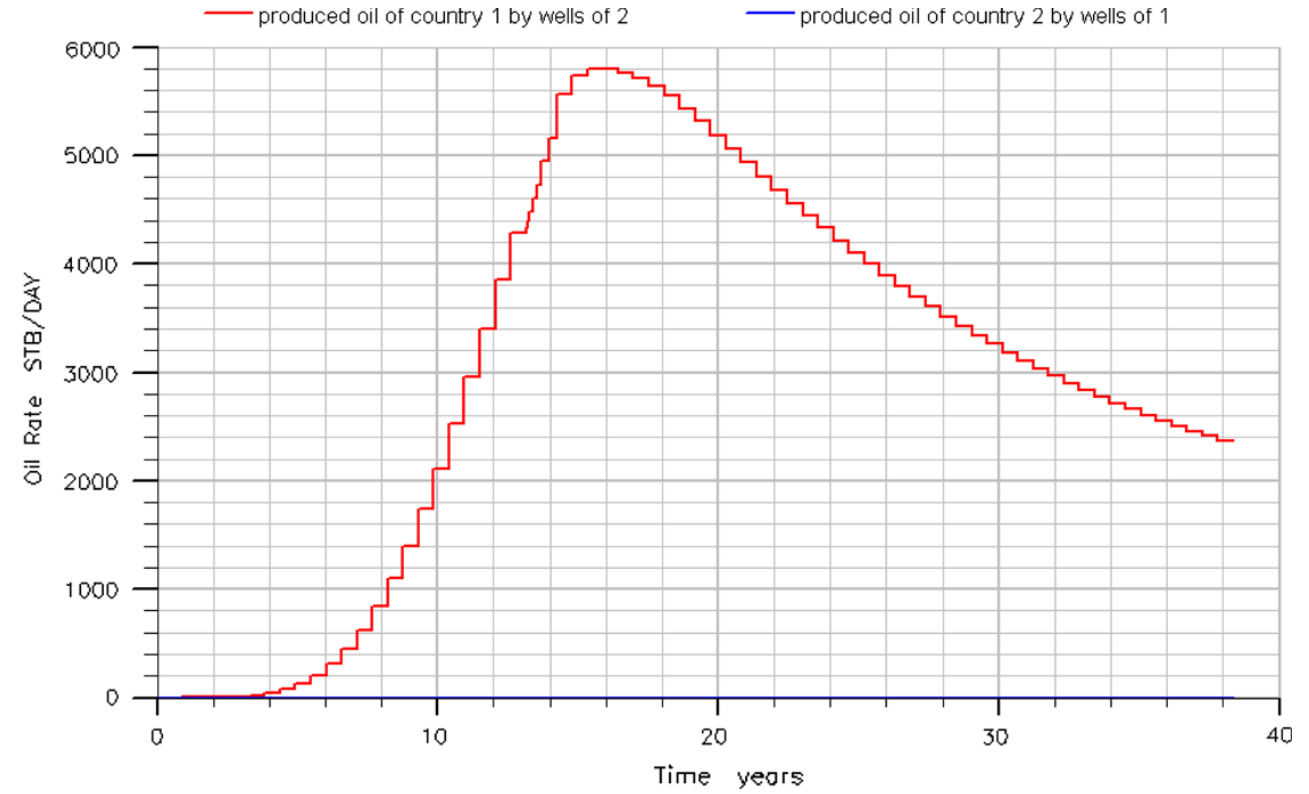

angle of $4.7^{\circ}$. Thus the part of reservoir under country 1 was located deeper down than the other half of reservoir.

Simulation results displayed that after 40 years of production with similar production conditions, the reservoir fluid migrates to the part of reservoir that is situated deeper down. Figure 13 demonstrates the results. The gravitational effects for our simulated reservoir were witnessed after 15 years of production and were measurable due to consistent conditions assumed throughout production time.
Furthermore, when the reservoir dip was increased from $4.7^{\circ}$ to $10^{\circ}$, the effects of reservoir slope becomes more severe. Figure 14 illustrates the influence of gravity on two tilted reservoirs having dip angles of $4.7^{\circ}$ and $10^{\circ}$.

Conclusively, the reservoir dip has an assessable influence on production. It will promote hydrocarbon fluid migration toward part of reservoir lying lower down and increases production in the same area. 

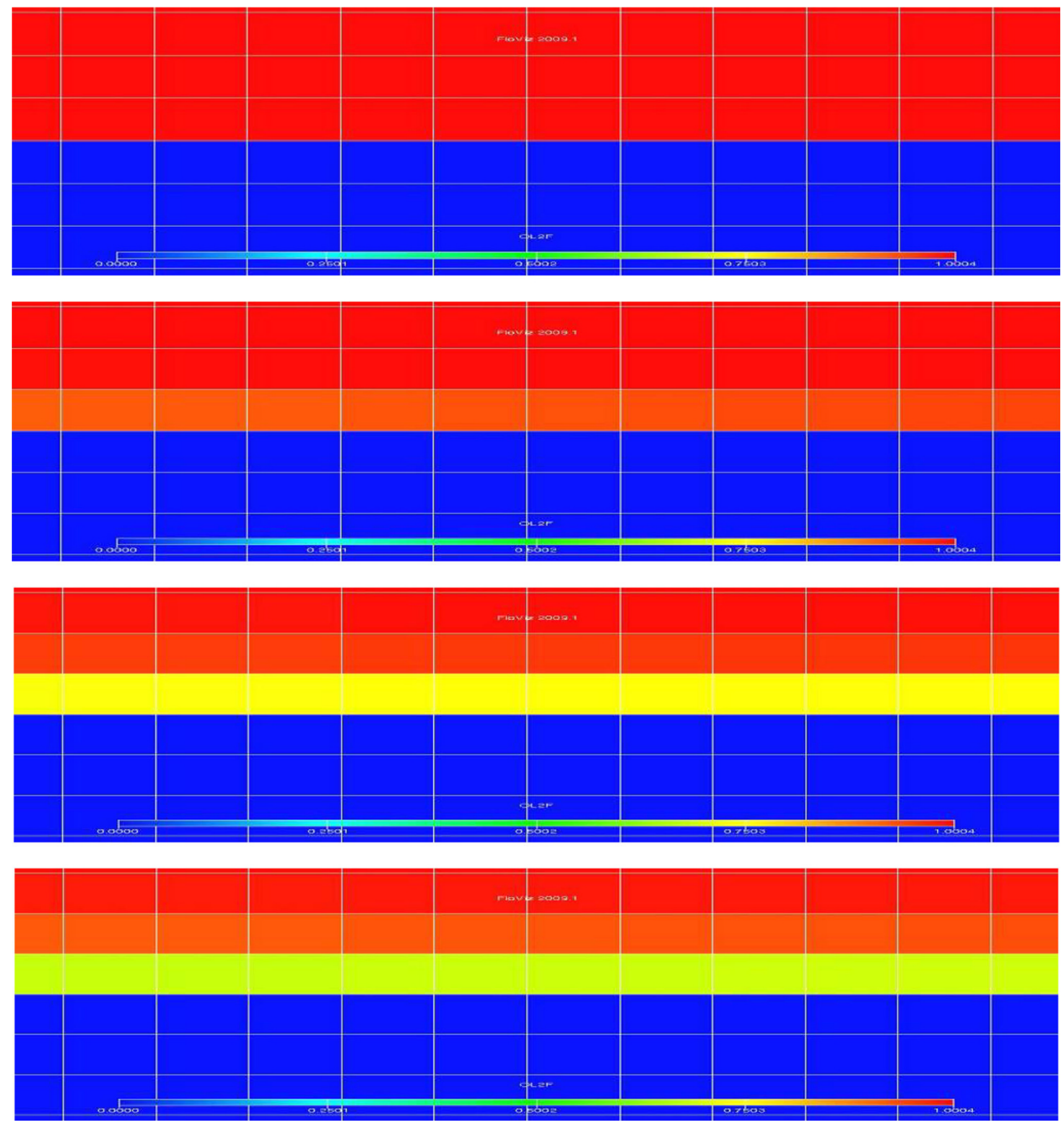

Fig. 11 Comparison of oil saturation at initial conditions (top) and migration across geographical border 3 years after (second down), 9 years after (third down) and 18 years after (bottom) the beginning of production

The effect of rock properties

To investigate the role of rock properties in production from a shared hydrocarbon deposit, we assume heterogeneity in the reservoir rock.

Permeability is a constant in the diffusivity equation and therefore we expect variations in permeability to affect fluid flow. To study the effects, permeabilities of 10 and $100(\mathrm{mD})$ are presumed for reservoir rock while all other influential factors are similar.

Simulation results demonstrate oil residing in part of reservoir with lower permeability migrates toward where permeability is higher. According to the diffusivity equation, the drainage radius develops more rapidly where 


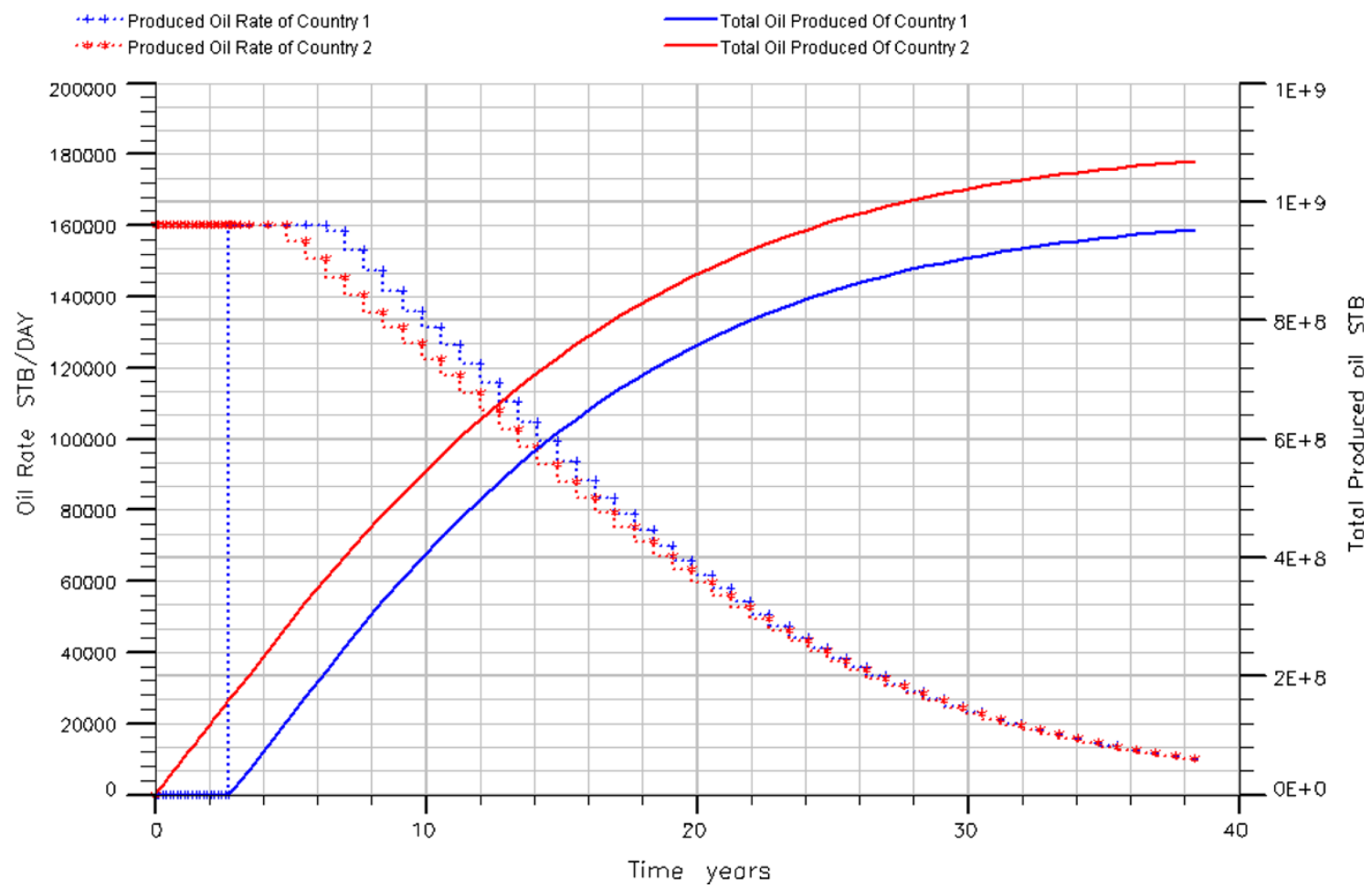

Fig. 12 Comparison of daily production flow rate and total production from a shared reservoir when country 1 begins production three years after country 2

Fig. 13 Oil migration across borderline in a tilted reservoir with a dip angle of $4.7^{\circ}$ after almost 40 years of production

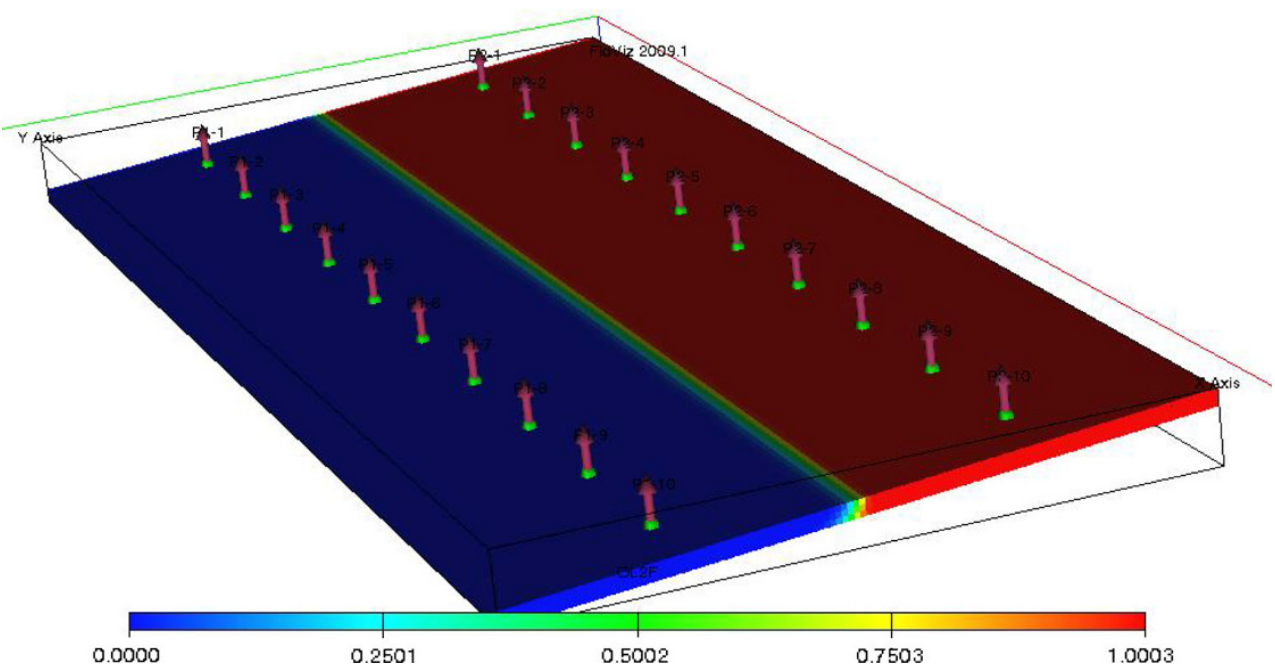

permeability is higher. Therefore production from the borderline will occur sooner where permeability is greater (Ahmed and McKinney 2005). Figure 15 illustrates total production and production flow rate of each country from such a reservoir. The graphs demonstrate that although territory with higher reservoir rock permeability will begin production at a higher rate, but production potential will decline faster that neighboring country with reservoir rock of lower permeability. Thus eventually, production within part of reservoir with lower permeability exceeds production rates encountered in neighboring country. Furthermore, since lower mobility ratios ensues lower permeability, the drainage radius will take longer to develop and more oil will be in place at any time, as demonstrated in Fig. 16.

Other than permeability, porosity is another rock property that influences fluid flow. Porosity affects production in two ways. First, higher porosities indicate presence of more oil in place and second, the diffusivity equation demonstrates that porosity is directly related to the time it takes for drainage radius to develop. Therefore, the lower 


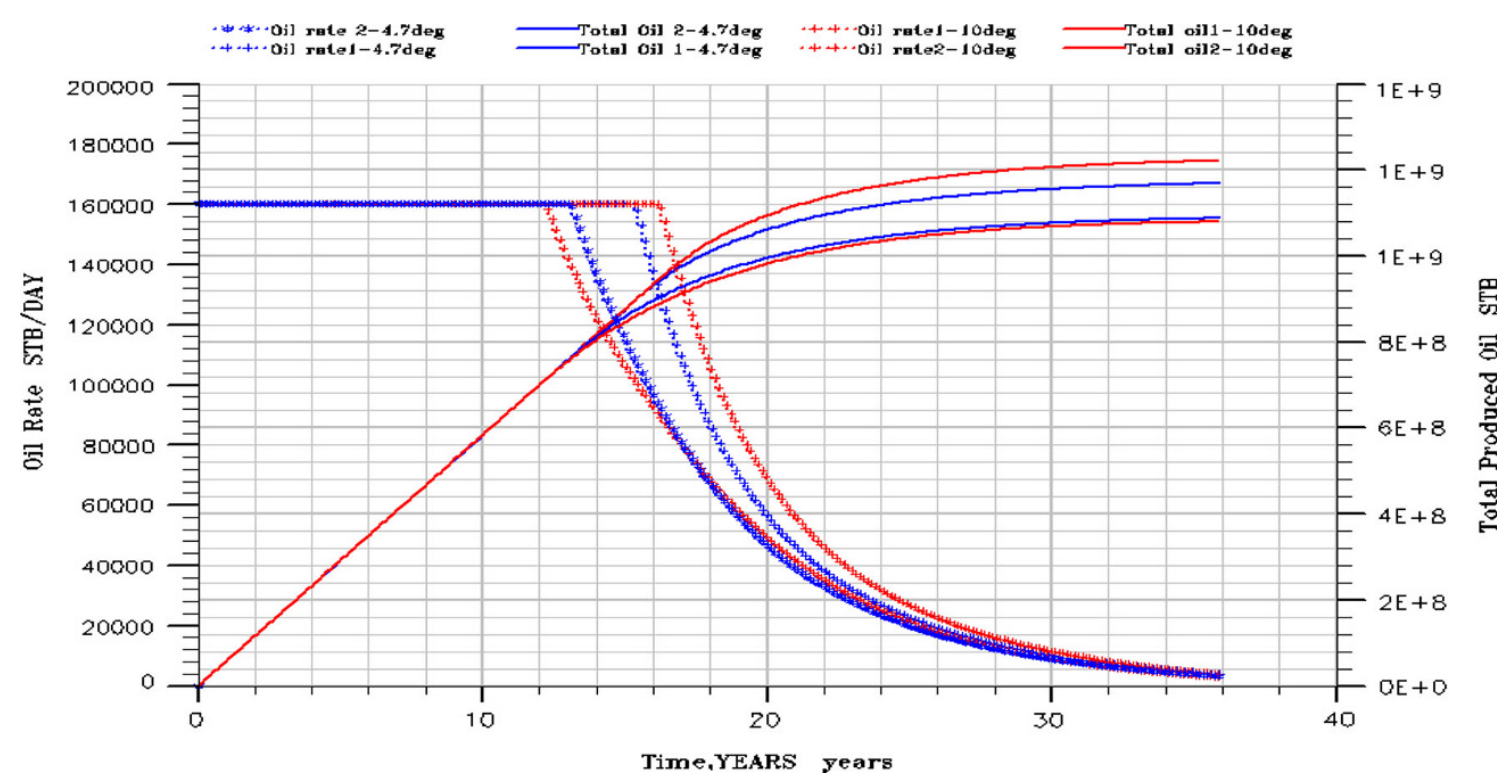

Fig. 14 Effect of dip angle on the oil flow rate and total oil production from a shared reservoir

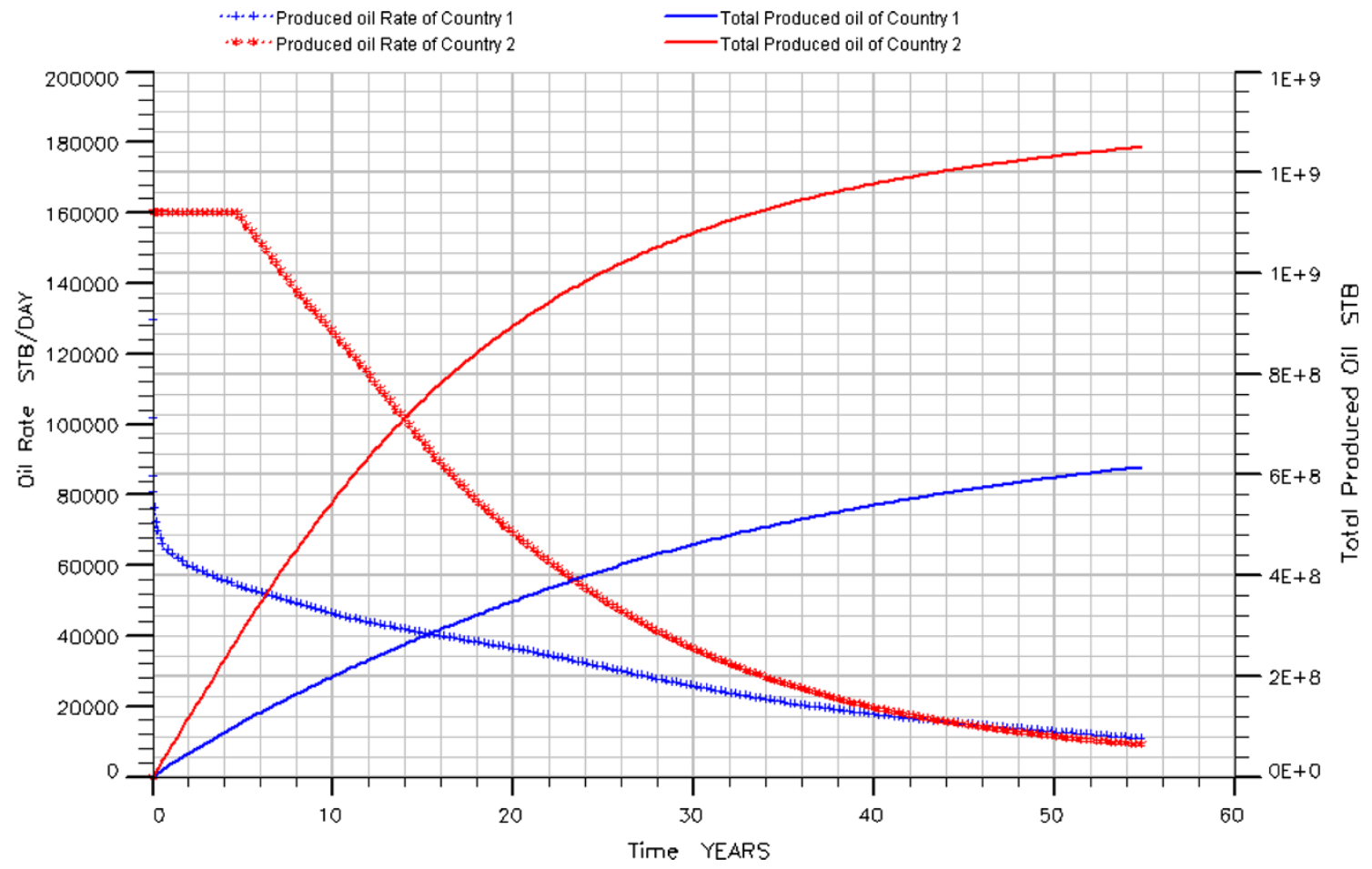

Fig. 15 Effect of permeability on the oil production flow rate and total production from a shared reservoir

the porosity is, the more rapidly the well drainage radius will reach the borderline.

Porosities of 10 and $30 \%$ have been assigned to reservoir within country 2 and 1, respectively. Results demonstrate that reservoir with lower porosity produces less oil. But the oil produced, although less than the neighboring country was more than what was initially present within the pores of less porous reservoir rock, considering the lower available oil in the less porous rock. Simulation results exhibited that even though the porosity of country 2 to 1 was $1 / 3$, the ratio of total produced oil of each country was $13 / 17$. Since $13 / 17$ is larger than $1 / 3$, country with less porous reservoir rock produced more than its initial oil in place of $1 / 3$. Figure 17 depicts the simulation results.

Although rock properties such as permeability and porosity are not elective properties and can hardly be 
Fig. 16 Comparison between pressure (top) and oil saturation (bottom) in a shared reservoir with varied permeabilities of 10 md (northern country) and 100 md (southern country)
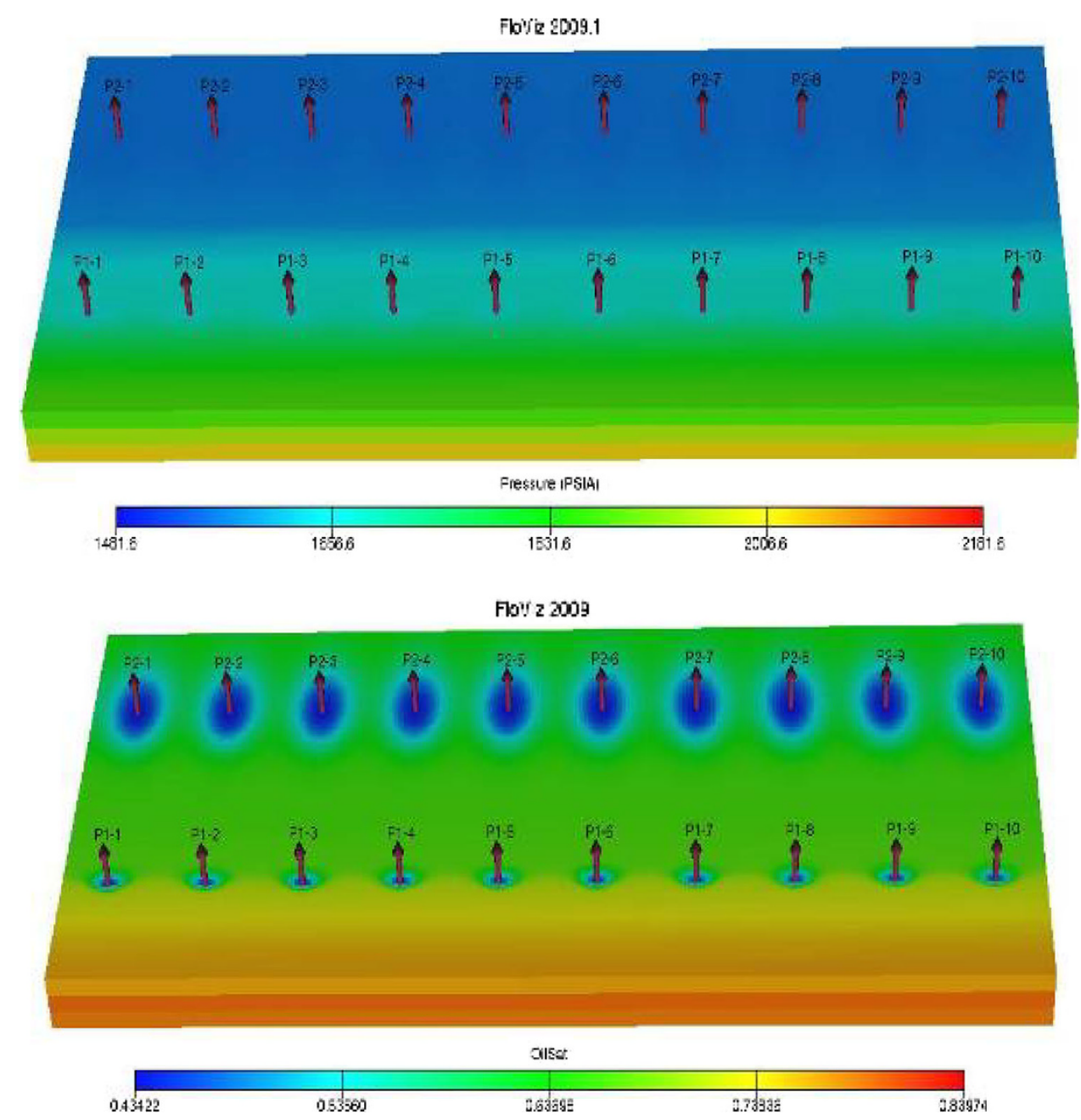

altered in large scales, but understanding their role and selecting means to manage their influences is vital when producing from a shared reservoir. Accordingly if a reservoir rock demonstrates heterogeneity, the long term effects of the rock properties has to be taken into account when planning reservoir production scenarios.

The effect of fluid properties

Fluid properties, similar to rock properties, affect production via two means. First, fluid properties directly affect production and second, according to the Darcy and diffusivity equations, fluid characteristics such as oil formation volume factor $\left(B_{\mathrm{o}}\right)$, viscosity $(\mu)$ and compressibility factor (c) influence fluid flow.

According to the Darcy equation, oil with higher formation volume factor $\left(B_{\mathrm{o}}\right)$ will be produced less than oil with smaller $B_{\mathrm{o}}$ when other influential factors are identical. The diffusivity equation constant, given by Eq. 6, suggests that viscosity and oil compressibility factor play roles that are analogous to the role of porosity.

Due to the resemblance of results to findings derived from analyses on rock properties, we exempt simulation results for this section.

The role of an aquifer

The presence of an aquifer, its ability to maintain pressure, outer boundary conditions, flow regimes and flow geometries directly influence production rates. For optimizing production, each country needs to study characteristics of aquifer in connection with their side of the reservoir. For this reason we've studied the role that an aquifer plays in a shared reservoir. We study the influence of an edge water drive on a reservoir-aquifer system.

A strong aquifer can impede pressure drop and maintain flow rates for longer periods of time by sweeping oil toward production wells of each country. The aquifer, 


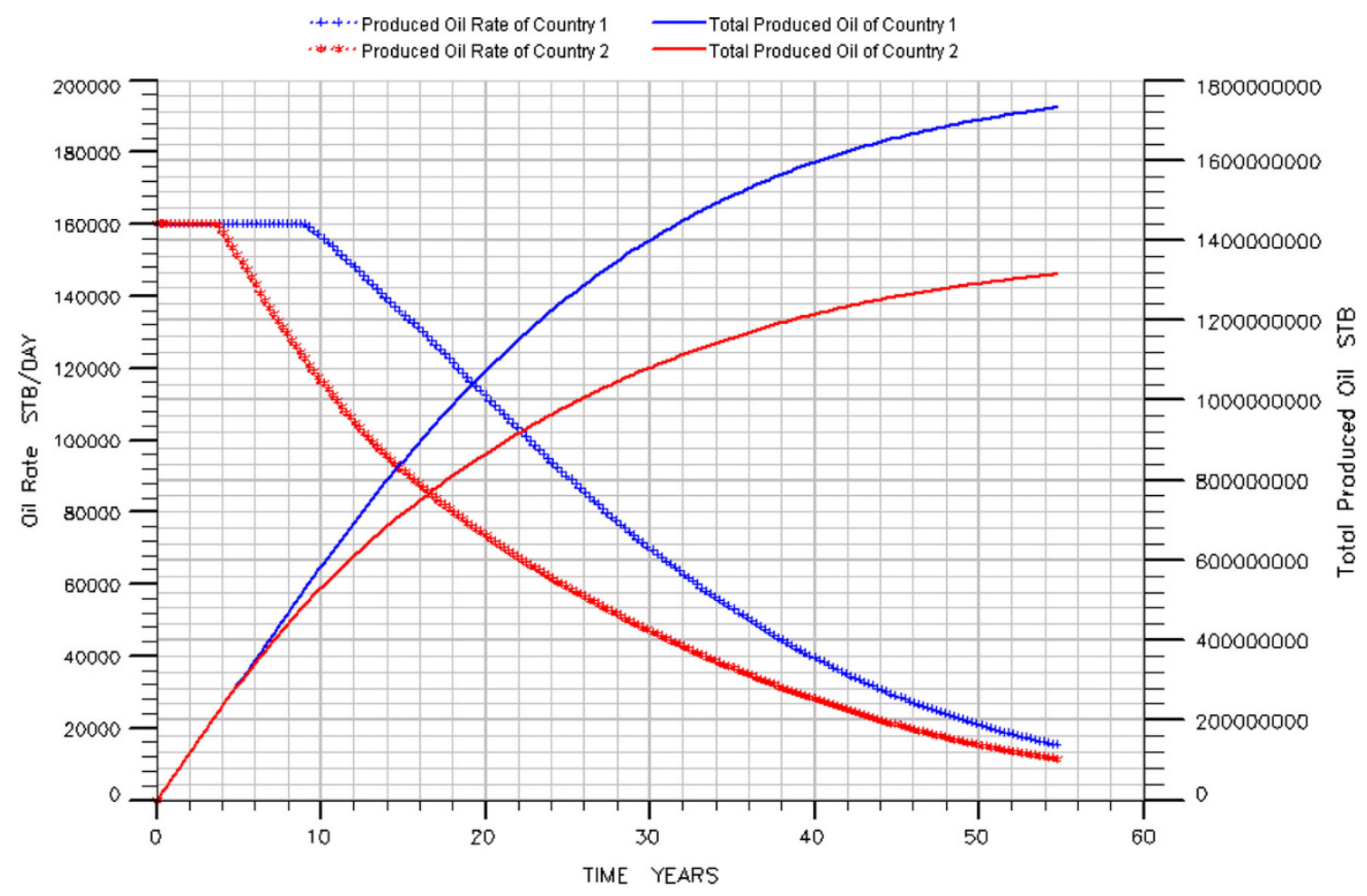

Fig. 17 Effect of porosity on the oil production flow rate and total production from a shared reservoir

Fig. 18 Oil saturation distribution in a producing shared oil reservoir with an edge aquifer

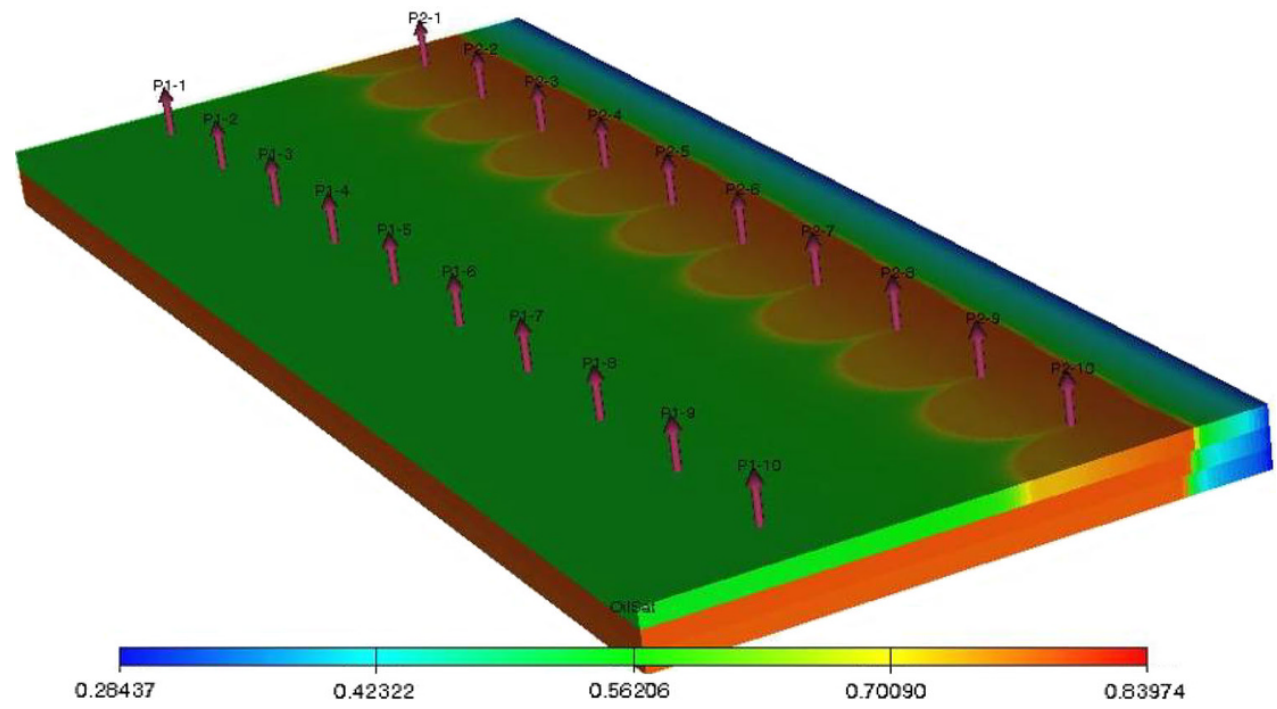

based on its capacity, can also impose oil migration. Figure 18 exhibits oil saturation in a shared oil reservoir with an edge waters that has been producing for 40 years. Although an aquifer may facilitate oil migration to the neighboring country, it will ultimately result in more oil production within part of the reservoir which it exists. As displayed in Fig. 19, at locations where the aquifer has entered the oil zone, oil has been swept toward production wells and consequently, even after 40 years of production, pressure and production rates have been maintained at desirable values of and 800 psi pressure loss and 40,000 STBD (Ahmed and McKinney 2005).

Evaluating joint management versus independent management of a shared reservoir

We intend to investigate the effect of a cooperative plan for reservoir development and production. If the results 


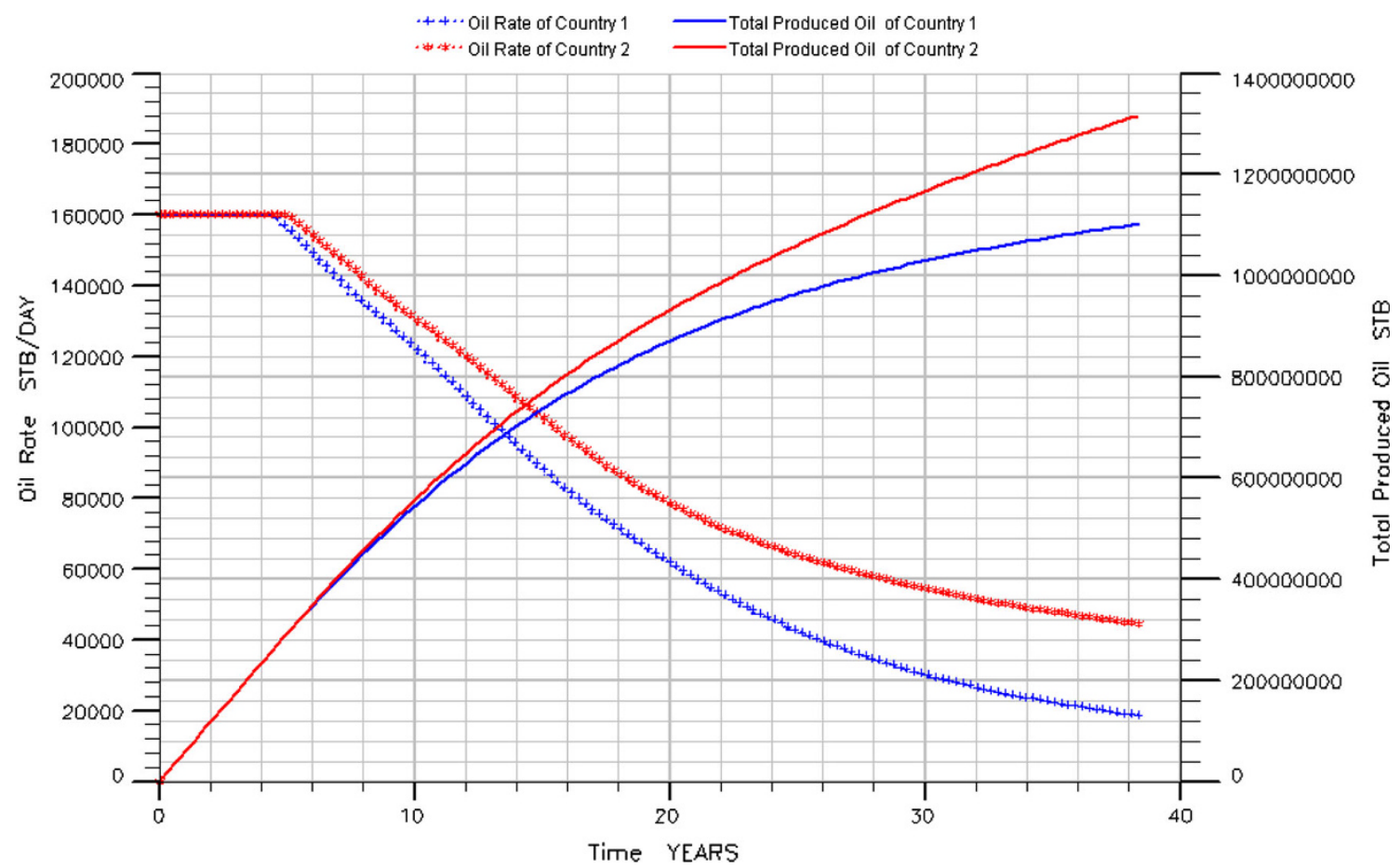

Fig. 19 Comparison of production oil rate and total production from a reservoir shared by a country with an edge aquifer (country 2) and without an aquifer (country 1)

demonstrate that the ultimate recovery of the reservoir will benefit both countries more than they can hope for when competitively exploiting the shared reservoir, then we can be hopeful to see the neighboring countries negotiating collaborative strategies for reservoir development.

Previously, we had assumed 20 flowing wells, 10 across each borderline producing at 160,000 STBD within each territory. Now we define 20 wells with 320,000 barrels of overall daily production configured as demonstrated in Fig. 20 bottom. Simulation results displayed in Fig. 21 demonstrate there isn't much difference between cooperative and competitive production from the shared reservoir. Despite the fact that central wells will allow production from a larger areal extent, but wells in previous configuration already encompassed the region as part of their drainage area. According to Fig. 21, total production and production rates confirm that a collaborative production may result in less production from the reservoir in comparison to independent production. Conclusively, if producers of a shared reservoir optimize production conditions for best ultimate recovery and least harm to the reservoir, there isn't much distinction between independent and cooperative production.

Even so, when countries are exploiting a reservoir independently, their sole objective is to produce more oil and disallow migration of hydrocarbon fluid to neighboring country and consequently not much attention is given to the reservoir or optimized production. The unscientific approaches taken by competing countries will inevitably decrease the ultimate recovery from a shared reservoir and this intensifies the importance of reaching a deal for production.

\section{Conclusions}

Initial study on the relationships of fluid flow in porous media, the Darcy and diffusivity equation in particular, suggest that the six influential factor of production from a shared reservoir are wells configuration, time of production, reservoir slope, aquifer performance, rock properties and the fluid properties across reservoir. Out of these 6 influential factors, the first two are determined by exploitation companies and the other four are intrinsic characteristics of the reservoir that with identifying them, we can optimize production by appropriate production schemes.

Simulation results illustrate that cooperative management of the shared reservoir isn't much different to when producing with similar production rates. Independent production may even lead to more produced oil for one country. 
Fig. 20 Comparison oil saturation in a shared reservoir after 40 years of production when the reservoir is independently produced (top) and jointly developed (bottom)
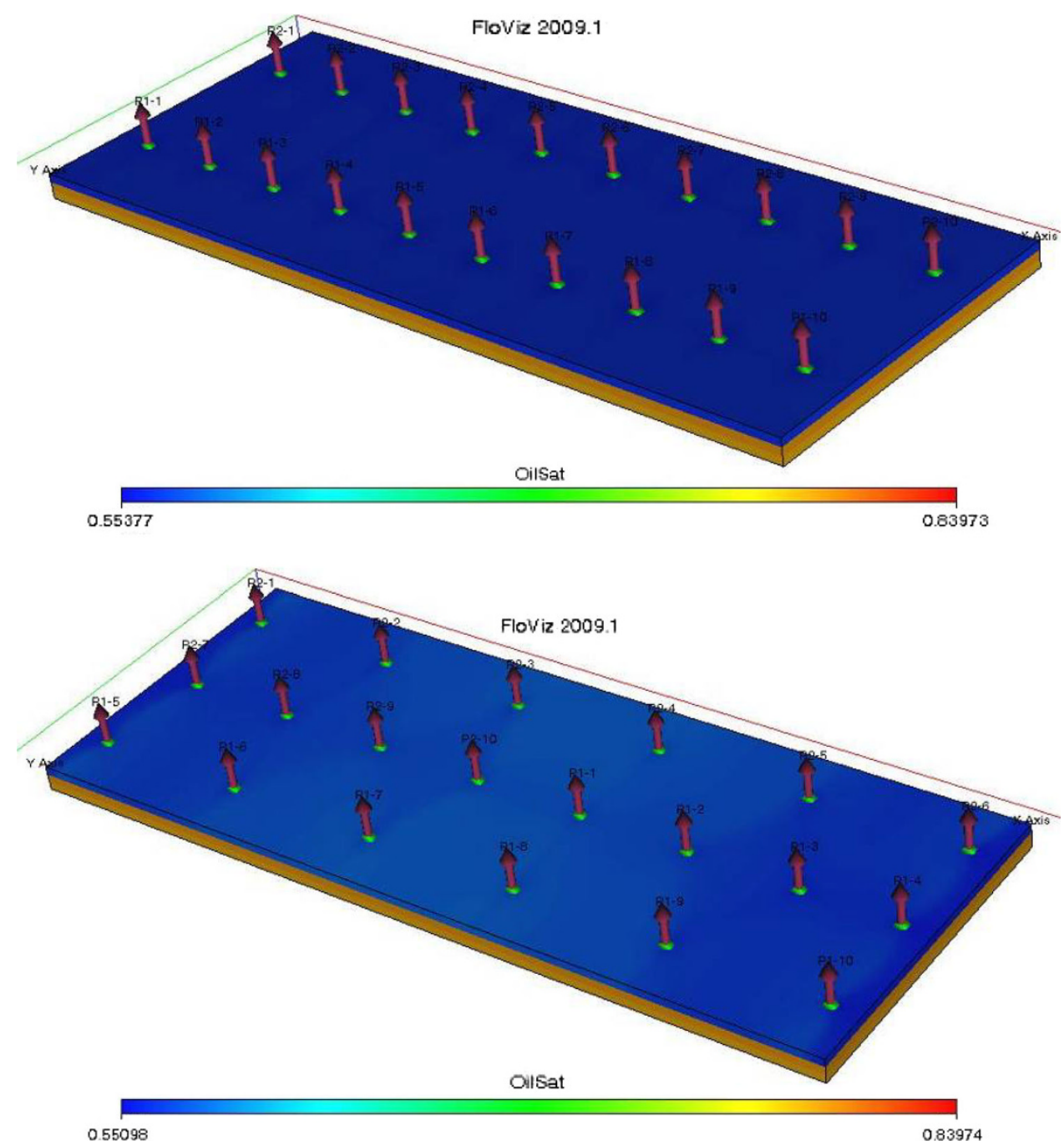

Investigation on time of production demonstrated that the country that begins production first will produce more oil than its neighboring country with equal number of wells and production rates. The country that begins production at a later time will only be able to save its share from what is left at the time of commencing production and will not be able to make up for the lost time.

We also concluded that the closer the wells are to the borderline, the higher is the chance of cross-border production. Oil tends to migrate towards the producing wells closer to the borderline. It's evident that the effect of time is best observable at the beginning of production but influences of well configuration are noticed at later times.

The effect of the reservoir slope exhibited that oil tends to migrate toward deepest part of the shared reservoir. This effect is usually observed halfway through reservoir production lifetime and only depends on the dip of the reservoir. As the dip increases the gravitational force also increase and migration intensifies.

Furthermore, Aquifer in the form of edge water can induce migration of oil out of the boundary but will hamper pressure decline and maintain flow rates and improve production in the country in which it is active. The benefits of an active edge aquifer are seen after few years of production and endure until reservoir abandonment.

Reservoir heterogeneities such as variations in rock or fluid properties can also influence production and ultimate recovery. The influences of porosity, permeability, viscosity and compressibility can be specified through the constant of the diffusivity equation given by Eq. 6 as $\eta=\frac{0.000264 k}{\varphi \mu c_{\mathrm{t}}}$. Considering $t \propto \frac{r^{2}}{\eta}$ which determines the time and therefore the velocity at which the radius of investigation progresses. Larger values (i.e. higher porosity, lower permeability, lower viscosity or lower compressibility.) 


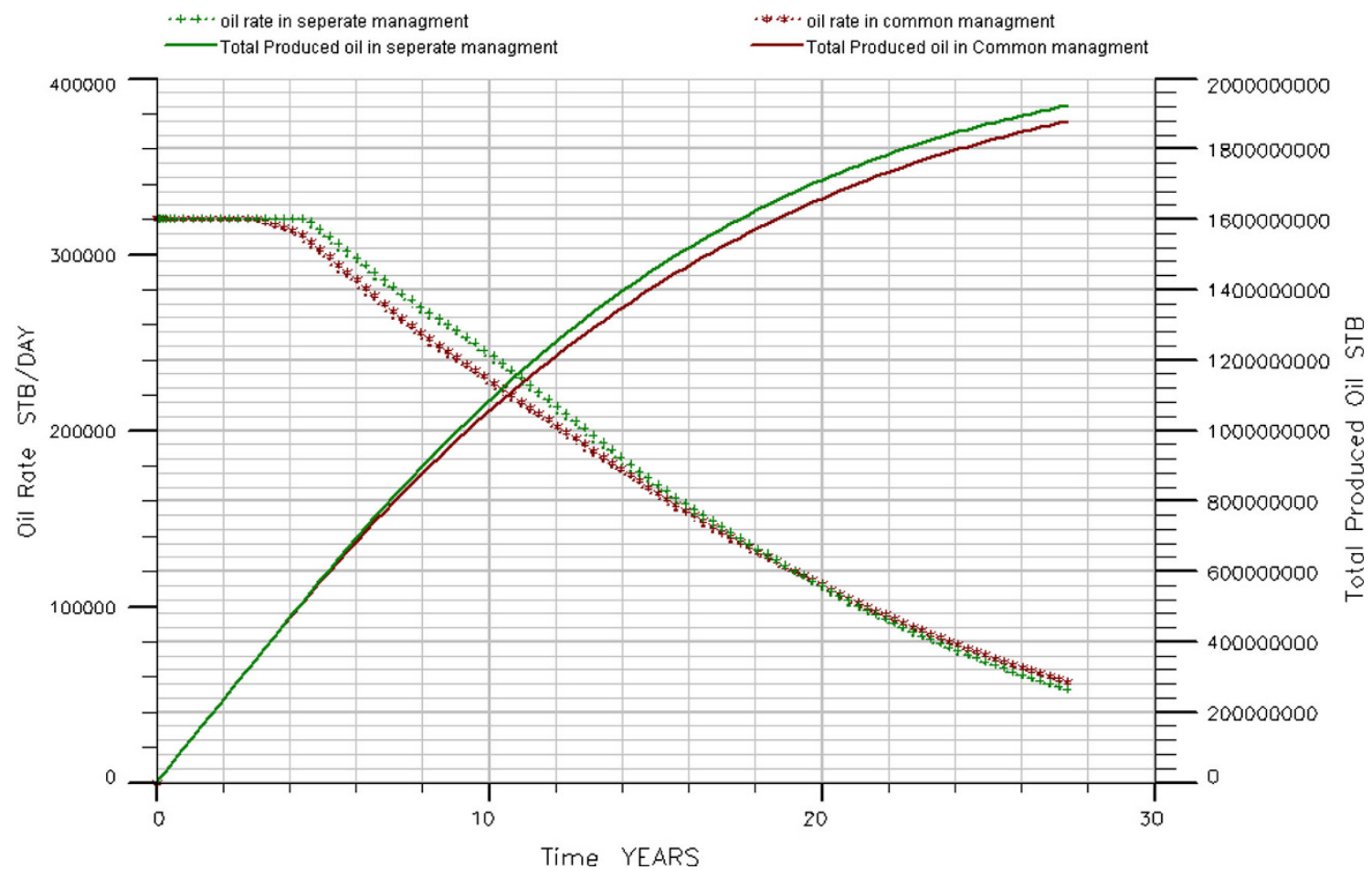

Fig. 21 Comparison of daily production rate and total production in a shared reservoir after 40 years of production by two addressed production scenario

indicate higher production rates and oil tends to migrate toward areas where $\eta$ is largest.

With all factors discussed, we can say that in a shared reservoir there is high competition between neighboring owners of the reservoir and it seems that the champion of such competition is the country who disregarding the reservoir's natural aspects like aquifer, rock and fluid property, will approach production with optimized engineering schemes. Consequently, independent countries that seek their nation's best interest should preferably negotiate a reservoir development plan with their neighboring country that allows fair exploitation and optimizes production in the long run.

Acknowledgments Special thanks go to the Arvandan Oil and Gas Company for providing required data and implementing commercial Eclipse software of (AOGC) with license agreement.

Open Access This article is distributed under the terms of the Creative Commons Attribution License which permits any use, distribution, and reproduction in any medium, provided the original author(s) and the source are credited.

\section{References}

Ahmed T, McKinney PD (2005) Advanced reservoir engineering unconventional gas reservoirs. Elsevier, Amsterdam, pp 187-290

Al-Hussainy R, Ramey HJ Jr, Crawford PB (1966) The flow of real gases through porous media. J Petrol Technol 18(5): 624-636

Ayala LF, Kouassi JP (2007) The similarity theory applied to the analysis of multiphase flow in gas-condensate reservoirs. Energy Fuels 21(3):1592-1600

Hou J, Luo F, Wang C, Zhang Y, Zhou K, Pan G (2011) Quantitative prediction model for the water-oil relative permeability curve and its application in reservoir numerical simulation. Part 1: modeling. Energy Fuels 25(10):4405-4413

Weems P, Fallon A (2012) Strategies for development of cross-border petroleum reservoirs. King \& Spalding: Energy Newsletter, Transactional Transactions 